\title{
Full-Spectrum Reproductive Justice: The Affinity of Abortion Rights and Birth Activism
}

\author{
JESSICA SHAW, \\ University of Calgary, Canada
}

\begin{abstract}
This paper argues that not only is there a relationship between birth activism and abortion activism, but that if empowering women is the goal, the two cannot be separated. By understanding how women's bodies have been controlled and their reproductive lives appropriated, the current pro-choice and birth activist frameworks that are used to advocate for women can no longer be understood to address women's needs. It is by working through the framework of full-spectrum reproductive justice that women may become truly empowered to regain control over their reproductive lives.
\end{abstract}

"Reproductive justice" is a term used to describe the link between reproductive health and social justice (Luna, 2010). It is based on the full realization of women's human rights, of which reproductive health is central (Ross, 2006). The recognition of the various intersecting identities that women have, such as race, class, sexual orientation, ability, language, religion, relationship status, age, national origin forms the basis for understanding reproductive justice (Ross, 2006; Silliman, Fried, Ross, \& Gutiérrez, 2004). The lack of sexual and reproductive rights for women is as related to these various identities as it is to gender inequality. This immediately separates it from other women's rights movements which have traditionally grown out of white, middle-class rhetoric. Reproductive justice highlights the inequality that exists regarding who can control their reproductive destiny and advocates for an end to structural power differences that prevent the empowerment of women (Ross, 2006). In order to accomplish this, colonization, industrialization, capitalism, and the imposition of patriarchy must be addressed. 
Typically, in Canada, the language of reproductive justice is used primarily in relation to abortion, but activists must recognise the need for both abortion advocates and birth activists to work together. Opposing abortion and normalizing overly medicalized births are both rooted in the subjugation of women. In order to emancipate women from sexist oppression and promote women's empowerment, activists in Westernized countries need to support both abortion rights and the de-medicalization of childbirth. However, the current pro-choice and birth activist frameworks, through which these arguments are generally discussed, are not sufficient in addressing the realities of women. In order to end reproductive oppression, activists must work collectively under a full-spectrum reproductive justice framework.

In order to fully understand reproductive justice, concepts such as reproductive oppression, medicalization, women's rights, abortion activism, and birth activism will be discussed in this paper. It is important to identify that these discussions will be specifically relevant to Westernized countries. While the focus of this paper is on women's reproductive health needs and the accompanying activism that is carried out in industrialized nations such as Canada, it is not my intention to downplay the significance of working towards ending maternal morbidity and mortality worldwide. The topics of concern regarding women's reproductive health needs may be different cross-culturally, but the goal of empowering women is the same.

I have chosen to use the term "activist" to refer to both individual advocates and to those who work at an organizational level. While there are many activists who work on reproductive justice issues, not all of them will use the language or subscribe to the principles of reproductive justice (Luna, 2010). This paper addresses activists who work on issues related to reproductive oppression, but do not yet subscribe to the language and ideology of reproductive justice. As a whole, reproductive justice encompasses much more than is presented in this paper, with the scope of this paper being limited to bridging the gap between abortion and birth activists.

\section{Reproductive Justice in the Context of Canada}

Reproductive oppression is defined as "the control and exploitation of women, girls, and individuals through our bodies, sexuality, labour, and reproduction" (Ross, 2006, p. 2). Women's various identities, especially their racial and socioeconomic identities, will have an impact on how they experience reproductive oppression. Both abortion activism and birth activism seek to end reproductive oppression by restoring the control of female reproduction to women.

In many parts of the world, abortion activism and birth activism revolve around the need for women to be able to access medical facilities, legal abortions, and skilled birth attendants. Worldwide, it is estimated that more than 358,000 women die (Connors, 2010) and between 15 - 20 million are injured and disabled every year from pregnancy and birth- related 
complications (Chowdhury, Koblinsky, Moran, \& Ronsmans, 2012). Having access to emergency medical services, safe abortion care, and sanitary birthing conditions is absolutely critical to protect the health and lives of women and their families (International Planned Parenthood Federation, 2006). Womancentered care needs to be the focus of abortion and birth services worldwide, but each country will have different issues that need to be addressed within the culture-specific context of women's rights. In Canada, and for the purpose of this paper, arguments around abortion are framed in relation to reducing stigma and increasing access to services, while arguments related to birth are framed around de-medicalization and the restoration of woman-centered practice as normal perinatal care.

Especially when considering how having access to medical tools and skilled professionals can be extremely beneficial for women with complicated births, it may be confusing as to why women's health advocates argue so strongly for the de-medicalization of women`s health. To clarify: de-medicalization is not advocating for the complete removal of medical knowledge and services from women's health care (Silliman, Fried, Ross \& Gutiérrez, 2004). Activists recognize that emergency medical care needs to be available for all women. The call for the de-medicalization of women's health is more a call for both the recognition of how women's bodies have been appropriated through patriarchal ideology and the desire for the control of women's bodies to be returned to women (Ross, 2006). Birth is an area where overly medicalized perspectives and interventions continue to harm women (Harper, 2005; Wolf, 2003). The control of the birthing experience is often placed unquestionably into the hands of medical professionals (Ehrenreich \& English, 2005). When this happens, women are no longer considered experts of their own needs and become bodies that have things done to them rather than full participants in the birthing process.

\section{Birth Activism: Normalcy Versus Illness}

Currently in Canada, birth activism refers to a movement that promotes woman-centered care and believes that women are capable persons who are able to competently make choices about their pregnancies and births. Birth activism generally promotes natural, unmedicated childbirth as leading to the optimal birthing experience, advocates for the ability of women to have control over their labour and birth in hospital settings, and promotes breastfeeding as normal and natural. Many birth activists have careers that revolve around their passion for woman-centred reproductive healthcare. These people are midwives, doulas, mothers, community members and sometimes physicians. In order to understand birth activism, it is important to understand the impact that the medicalization of birth has had on women's lives (Bergeron, 2007; Brodsky, 2008; Ehrenreich \& English, 2005; Harper, 2005; Janssen, Hendersen \& Vedam, 2009).

The medical model of childbirth, under which nearly $95 \%$ of women in 
North America give birth, is based on the medicalization of birth and the control of women's bodies (Harper, 2005; Janssen, Hendersen \& Vedam, 2009). Medicalization can be defined as the "biomedical tendency to pathologize otherwise normal bodily processes and states... [It] leads to incumbent medical management [and is] a social process whereby an expertbased biomedical paradigm dominates discussion of health and frames it in negative ways, usually as illness" (Parry, 2008, p. 785). When natural physical processes are framed as illnesses, they become defined on a scale that ranges from normal to pathological, which can alienate people from regular experiences such as aging, death and birth (Bergeron, 2007).

The history of the medicalization of women's bodies, especially as it relates to their reproductive lives, is well documented. Entire books chronicle the various ways in which women have been subjugated in their roles related to pregnancy and birth (see for example, Brodsky, 2008; Ehrenreich \& English, 2005; Wolf, 2003). The medicalization of childbirth is a process that took place over much of the nineteenth century and continues today (Harper, 2005). In an attempt to discredit female healers and midwives, the medical profession promoted technical births as an indicator of class status (Brodsky, 2008; Ehrenreich \& English, 2005). By the early twentieth century, the superiority of physicians who promised "civil births" in the name of science and the desire for women to prove their class status by being able to have "high-class medicalized births" became the norm (Harper, 2005, p. 33). As the fad of hospital-based births continued, the credibility and knowledge of midwives and traditional healers were forcibly lost. Narratives, hospital records and memories document how labour was appropriated as something to be medically managed and controlled by typically male physicians who operated according to their schedules and perceptions about the need for efficiency (Brodsky, 2008; Ehrenreich \& English, 2005; Harper, 2005).

Unfortunately, once medical interventions became routine, the concept of what a normal birth looks like changed. Whereas for millions of years, normal or natural birth for women generally consisted of a non-medicated vaginal delivery, over the past few decades in North America, birth has become more medicalized and less reliant on women's innate birthing abilities (Brodsky, 2008; Ehrenreich \& English, 2005; Harper, 2005). As birth stories and prenatal classes began to discuss birth in medical terms and medical interventions as common procedures that are required for the normal progression of labour, the concept of what a normal birth ought to be like changed. For example, it appears to be a current, commonly held belief that it is normal for a woman to labour and give birth lying down. The reality is, this position works against gravity and against the body's natural urge and desire to labour in a position that promotes the downward movement of the baby through the birth canal (Simkin, 2001). This position, called the supine position, literally means, "lying face upwards...inert, indolent, morally or mentally inactive" (Barber, 2004, p. 1562) and was likely introduced and promoted as the best position to give birth in order to facilitate the comfort of the physician who could just sit at the end of the bed, see everything and 
extract the baby. The loss of confidence that women can experience over their lack of control when birthing is a contributing factor to the disempowerment of women (Bergeron, 2007; Lothian, 2006; Lowe, 2004).

Since medicalization has led to women's pregnancies, labours and births being viewed as conditions to be treated rather than as natural processes, a defining characteristic of birth under the medical model is that there are often many medical interventions that are used (Bergeron, 2007; Munro, Kornelsen, \& Hutton, 2009). Some of the most common interventions currently used during labour and birth in North America include: ultrasound, amniocentesis, electronic foetal monitors, induction, intravenous hook-ups, spinal analgesia, general anaesthetic, episiotomy, forceps, vacuum delivery and Caesarean section (Lothian, 2006; Parry, 2008). These interventions continue to be routinely used despite the fact that their use was decried as generally unnecessary in a 2008 joint policy statement by the Society of Obstetricians and Gynaecologists of Canada, the Association of Women's Health, Obstetric and Neonatal Nurses of Canada, the Canadian Association of Midwives, the College of Family Physicians of Canada, and the Society of Rural Physicians of Canada (Society of Obstetricians and Gynaecologists of Canada et al., 2008). Furthermore, restrictions on eating, drinking, movement and positioning are often imposed on women birthing in hospitals (Klaus, Kennell, \& Klaus, 2002). The safety of the woman in labour and her infant is affected when routine medical interventions and controlling restrictions compromise the woman's ability to labour naturally.

Studies show it is often the seemingly benign initial medical intervention that leads to complications which, in turn, lead to the purported need for further medical interventions (Cohain, 2007; Lothian, 2006). Often, these interventions are suggested to women by medical professionals who have trained under the medical model and may have never seen a natural birth (Harper, 2005; Klaus, Kennell, \& Klaus, 2002). The literature highlights that even when a woman desires a birth without medical intervention, caregivers working under a medical model may favour and promote a medicalized approach to birth (Baker, Choi, Henshaw, \& Tree, 2005; Lahood, 2007) . A common example of how the introduction of an intervention can lead to a highly medicalized, surgical birth is when a woman's labour is induced or augmented with Pitocin, a synthetic drug that simulates oxytocin and causes contractions (Brodsky, 2008). Unfortunately, the contractions caused by Pitocin are generally longer and stronger than natural contractions (Cohain, 2007). Women who have Pitocin are less likely to be able to cope with the pain of their contractions and often request pain medication. When the ability to feel contractions is dulled, women may be unable to vaginally birth their babies and a Caesarean section is often recommended as a necessary intervention (Brodsky, 2008; Cohain, 2007).

Although they are common, Caesarean section births are major abdominal surgery. As a result of medicalization, and in spite of the fact that the World Health Organization and other medical professional organizations suggest that no more than $10-15 \%$ of births be by Caesarean delivery, currently in 
North America the Caesarean rate is around 30\% (Chaillet et al., 2007; Munro et al., 2009; Parry, 2008). This is problematic because complications arise for both women and babies when unnecessary Caesareans are performed. Citing reports from Amnesty International, the Center for Disease Control, the California Public Health Department, and a longitudinal study on maternal morbidity in the United States, Roth and Henley (2012) reveal that, "dramatic rises in caesarean rates have coincided with increasing maternal deaths, a significant portion of which are connected to unnecessary caesareans" (p. 207). If women were allowed to labour naturally, without the introduction of unnecessary medical interventions, the rate of Caesarean births would significantly decline (Cohain, 2007).

Having control over one's health care decisions is critical, and numerous authors have documented how important it is that women have absolute control over their pregnancies and births in order to have positive birthing experiences (see for example, Baker, Choi, Henshaw \& Tree, 2005; Goldberg, 2009; Hardin \& Buckner, 2004; Janssen, Henderson \& Vedam, 2009; Lothian, 2006; Parry, 2008). Working from the premise that "a satisfying birth will have a lasting positive effect, just as a traumatic or unsatisfying birth will have a negative one" (Lothian, 2006, p. 297), it is understood that giving birth is a powerful, life-changing event that affects women and can either empower or disempower them about their ability to care for their families in the future (Carlton et al., 2005; Jordan \& Murphy, 2009; Lowe, 2004). Goldberg highlights that there is a positive correlation between how women feel about being in control of their birthing experience and how they feel about their babies in the postpartum period. Having control over one's birth experience can lead to an increased sense of responsibility for the health of oneself and one's baby, a shorter recovery period, enhanced emotional wellbeing, a sense of empowerment and boosted self-esteem (Goldberg, 2009). The ability of pregnant women to control the environment that they labour in, the caregivers who tend to them, the people who are present during labour and birth, the positioning that they labour in, and the interventions that are used is documented in birthing literature as being critical for the empowerment of women through childbirth (Carlton et al., 2005; Hardin \& Buckner, 2004; Janssen et al., 2006; Lothian, 2006; Price, Noseworthy, \& Thornton, 2007).

Another aspect of maternal health that has been medicalized and stigmatized is breastfeeding. The benefits of breast milk over formula have been welldocumented and suggest that breastfeeding is indisputably the optimal way to provide infants with all of their nutritional needs and to promote bonding between a mother and her baby (Huggins, 2005; Klaus et al., 2002; Minister of Public Works and Government Services Canada, 2002; Simkin, 2001). In fact, studies have found that, especially in developing countries, infants are twenty-five times more likely to die when they are fed infant formula over of breast milk (Harper, 2005). Breast milk is perfectly designed to meet the nutritional needs of infants, and to provide protection against illness both during and after the breastfeeding years (Huggins, 2005). Furthermore, breastfeeding promotes bonding and healthy attachment between mothers 
and their children, and leads to healthier childhood mental and physical developments (Harper, 2005; Huggins, 2005; Klaus et al., 2002; Simkin, 2001). Health Canada, and other national and international organizations, recommend exclusive breastfeeding for the first six months of an infant's life, and then sustained breastfeeding for approximately two years after that (Minister of Public Works and Government Services Canada, 2002). In most parts of the world, breastfeeding is the only way to nurture an infant. Yet in Canada and other Westernized countries, breastfeeding is framed in terms of being a mother's choice rather than in terms of nutrition. It is for this reason that anthropologists deem the discontinuation of breastfeeding as a negative indicator of how immigrant families acculturate to Westernized standards (Agnew, Gilmore, \& Sullivan, 1997). With all of the benefits of breastfeeding, it may be difficult to understand why some women choose not to breastfeed. For some women, not breastfeeding may be related to illness or disability, or because it would impede their ability to work outside of the home (Huggins, 2005). For other women, not breastfeeding is a choice unrelated to ability or necessity and is more related to the ways in which formula feeding has been promoted as normal in society (Huggins, 2005). This normalization is directly related to the medicalization of women's bodies to support consumeristbased capitalism (Ehrenreich \& English, 2005).

Current publicized examples show how breastfeeding is still considered taboo in Canadian culture. In 2008, a woman was ushered out of a clothing store in Vancouver, British Columbia after she started breastfeeding her baby. Apparently a store staff member told the mother that she was offending other customers. At the time, the mother did not know that she had the legal right to breastfeed in public, and was quoted as saying she felt "humiliated" (CBC News, 2008b). Of the incident, Dr. Verity Livingstone of the University of British Columbia's Vancouver Breastfeeding Centre said, "Whenever a woman is told breastfeeding is offensive or indiscreet, it's shaming new mothers for doing what's right" (CBC News, 2008b). Similarly, even though it is well established that breastfeeding helps relieve infant discomfort caused by the change in pressure during the take-off and descent of a flight, women have reported being asked to cover their breasts with a blanket while breastfeeding onboard airplanes (CBC News, 2008a). The problems that exist related to women breastfeeding in public stem from the objectification of women's breasts as objects of sexual attraction rather than as a natural food source. This is clearly evidenced in the media and on social networking sites such as Facebook. Facebook is a social networking tool where people create public profiles about themselves and can post notes, send messages and display photos. Consistently on Facebook, photos of women breastfeeding are deemed "obscene" and removed by the website managers, whereas highly sexualized images of women remain (Muir, Larner, Bee, Joseph, Calvert, Slamen, \& Muir, 2010). Groups have been formed to protest this practice, the largest of which is called "Hey Facebook, breastfeeding is not obscene!" (Muir et al., 2010). This group states, "nursing moms everywhere have a right to show pictures of their babies eating, just like bottle-fed babies have 
a right to be seen" (Muir et al., 2010). By the end of 2010, over a quarter of a million Facebook users had joined this group. Breastfeeding activists and birth activists advocate that breastfeeding be viewed as a natural and normal component of motherhood and infant wellness. The goal is to de-stigmatize public breastfeeding and recreate a culture where both breastfeeding, and seeing women breastfeed, are once again common experiences.

Overall, birth activists maintain that in order to restore the dignity that has been taken from women by colonization and the historically male-dominated medical institution, it is important that women understand the myths, concerns and realities surrounding both natural birth and breastfeeding. Normal childbirth needs to be redefined to reflect women having complete control over decisions related to their births. Activism to promote the demedicalization of birth and breastfeeding is needed in order for women to be able to resist birthing under an oppressive guise of care that is patronizing and disempowering (Ehrenreich \& English, 2005).

One way that women resist the medicalization of their bodies and their births is through midwifery care. Midwifery care differs from physician-based care in that it looks beyond the need for physical wellness only and promotes the importance of facilitating births that are both empowering and celebratory (Cohain, 2007). Whereas 53\% of Canadian women rated their births with a physician as "very positive," $71 \%$ of women under midwifery care rated their births this way (Shaw, Ormiston \& Weeds, 2008). Furthermore, the health outcomes of women and babies under midwifery care are excellent, with fewer Caesarean sections and a lesser need for medical interventions (Shaw, Ormiston \& Weeds, 2008). Midwifery care seeks to honour and empower women to have control over their birthing experiences, thus freeing them from the patronizing care that often exists under the medical model. Unfortunately, midwives are not uniformly covered by health care benefits, and many women in Canada still have to pay for their midwifery care (Canadian Association of Midwives, 2012). Since the second- wave feminist movement, health advocates have supported the resurgence of midwifery as an important aspect of women's reproductive health (Craven, 2010; Spoel \& James, 2006). While discrepancies in care still exist, women are taking action to secure reproductive justice through birth choice (Craven, 2010).

While women are vocal about the need for midwifery care in order to regain control over their bodies, there is an aspect of reproductive health that many birth activists are silent about: the importance of women having access to abortion services. In focusing so strongly on the ways in which women are oppressed during labour and birth, activists often fail to recognize that it is the same social and medical structures that stigmatize natural birth and breastfeeding that also stigmatize abortion (Ross, 2006). This is a huge gap in a movement that purports to be entirely focused on woman-centered care. Midwives, doulas, and other birth activists have the responsibility to understand how abortion rights are maternal rights; and to advocate for awoman to be able to control all aspects of her pregnancy, beginning with whether to continue it or terminate it. Currently, it appears that advocating 
for anything related to abortion is left for the abortion rights movement to address.

\section{Abortion Activism: Normalcy Versus Stigma}

It is estimated that between 20,000 and 120,000 illegal abortions occurred annually in Canada prior to the decriminalization of abortion (The Childbirth by Choice Trust, 1998). As highlighted by The Childbirth by Choice Trust, many of these were performed by persons without medical knowledge or the proper tools, and it was common for women to be injured or die from abortion-related complications. In hospitals, entire wards were dedicated to treating women who had complications related to unsafe abortion. We know from our own history and from looking at countries where abortion is still illegal that women will always seek abortion services, regardless of its legality, regardless of its safety, and regardless of whether or not it is considered a moral choice (Shaw, 2006). When abortion is illegal, women are forced to have abortions in secrecy, often in clandestine conditions and without proper medical attendants or tools (Shaw, 2006; The Childbirth by Choice Trust, 1998). In many parts of the world, unsafe abortion is still the leading cause of death for women, with annual numbers estimating that over 70,000 women die from abortion- related complications worldwide (International Planned Parenthood Federation, 2006). The medicalization of the abortion procedure is an important step in preventing the potential infection and death of thousands of women. In Canada, where medicalized abortion care is now the norm, abortion rights activism focuses on the need to address the other barriers that women still face in trying to access abortion services (Shaw, 2006).

In 2010, the most recent year with national abortion statistics, 64,641 were provided in Canada (Canadian Institute for Health Information, 2012). This number can be considered a low approximation because the data is incomplete for British Columbia and statistics were not collected for the province of Québec (Canadian Institute for Health Information, 2012). Furthermore, the national survey does not account for medical drug-induced abortions, self-procured abortions, or abortions done in the United States for Canadian women (Flaherty, 2003). In the previous national report, where Québec abortions were included, the national abortion rate was 96,815 (Statistics Canada, 2008). This is likely closer to the actual number of abortions done in Canada.

As one of the most frequent outpatient procedures performed on women, and as something that nearly 1 in 3 women will experience at some point in their lives, abortion is extremely common (Guttmacher Institute, 2010). However, despite its, abortion is highly stigmatized. As the research coordinator at Canadians for Choice, I spent three months "undercover," pretending to be a pregnant woman seeking abortion care. I called every hospital in Canada and documented the information that I was given and the 
way that I was treated. Through this exercise, I learned of the many myths, misconceptions, and scare tactics about abortion that are often propagated by misinformed or judgemental people. I also learned of the compassionate care that many abortion providers offer. Through these experiences, I have been able to connect and converse with many people who fight for abortion rights, both those who identify as pro-choice and those who identify as advocates for reproductive justice.

The ensuing report on the research project that I did with Canadians for Choice was published as "Reality check: A close look at accessing abortion services in Canadian hospitals" (Shaw, 2006). In it, some of the most prevalent barriers that women in Canada face in relation to abortion are discussed. Some of these include an insufficient number of abortion providers, long wait-times to access services, cost and travel difficulties, and anti-abortion pressure. Women in marginalized communities, such as Aboriginal and coloured women, immigrant women, rural women, and poor women are disproportionately affected by the laws that surround abortion.

In Canada, fewer than $16 \%$ of hospitals provide abortion services, and there are only 33 abortion clinics across the country (Shaw, 2006; Wu \& Arthur, 2010). Although any hospital equipped with an obstetrics ward is capable of performing abortions, there are few physicians trained and willing to offer the service (Shaw, 2006). This may be based on a combination of a fear of harassment, as anti-abortion extremists continue to target abortion providers and their families, and on the lack of training available in Canadian medical schools. One study found that nearly $40 \%$ of Canadian medical schools do not teach any aspect of abortion in the pre-clinical years and that more class time was spent discussing Viagra than abortion law, policy, procedures, and pregnancy options counselling combined (Koyama \& Williams, 2005). Not having enough abortion providers can lead to long waiting periods for women. As abortion is a time-sensitive procedure, this can be a huge and distressing impediment. For some women, the option of travelling to another community to obtain an abortion may be appealing, but this can be costly in both time and money (Shaw, 2006).

The cost and travel difficulties related to obtaining abortion services are issues for many women who do not live near an abortion provider or for women who do not have healthcare coverage. Given that in Canada, most abortion clinics and hospitals that provide abortion services are located within 150 kilometres of the Canada-United States border, having to travel to access abortion services is often a reality (Shaw, 2006). Although travel grants may be available for some women, they are generally offered as reimbursements rather than as funding that is provided in advance. Women who must travel to access abortion services may have to take time off of work or school, arrange for childcare or eldercare, and explain to family and friends why they need to go out of town for a few days. For those who live in a community where abortion services are available, costs may be related to their not having healthcare coverage, as is the case for many immigrant women and visitors to Canada. Furthermore, although abortion is covered under provincial and 
territorial healthcare, some provinces have strict requirements about how the abortion must be accessed in order to be eligible for coverage, and many provinces exclude abortion as a medical service eligible for interprovincial reciprocal billing (Shaw, 2006). In New Brunswick, for instance, abortion services are only covered when done at a hospital, after the referral of two physicians (Shaw, 2006). On Prince Edward Island, abortion services are non-existent, and all women requiring abortions, currently over 115 per year, must travel out of province (CBC News, 2010). Arranging travel to access a healthcare service is something that often requires a person to go through several people. Whenever a woman is forced to go through multiple gatekeepers in order to access abortion services, they run the risk of encountering anti-abortion sentiment.

Anti-abortion protesters and organizations are a dangerous force when it comes to attacking women's rights (Arthur, 2003; Shaw, 2006). The antiabortion movement believes that the foetus has a right to life that supersedes a woman's right to control her reproduction. As part of a movement, followers often engage in activities that condemn abortion and stigmatize women who have abortions. Some of these activities include: protesting outside of abortion clinics and hospitals, operating "crisis pregnancy centres" that deceive pregnant women about the abortion procedure, setting up graphic displays on university campuses and in public spaces that compare abortion to genocide, and lobbying politicians to create laws that would recriminalize aspects of abortion (Arthur, 2003). Arthur, an abortion rights advocate, asserts that anti-abortion supporters are often religious, and can be found in practically every sector of society. In most countries, there are entire organizations that dedicate themselves to ending abortion. These organizations are effective in propagating myths about abortion and in using skilled public speakers to try to discredit the abortion rights movement. A common argument used by anti-abortion advocates is that a foetus is a human being and therefore has a right to life (Canadians for Choice, n.d.). If one agrees to the terms of this argument, it can still be argued that abortion needs to be a viable choice for women, based on a person's right to self-determination. I would argue that until birth, a foetus primarily impacts the woman who is pregnant with it. The foetus relies on the woman for nourishment and life. In no other circumstance would we argue that if a person needs to be attached to another person in order to survive, then the individual rights of the supporting person are forgone. For example, if a person requiring dialysis twenty-four hours a day could only survive if attached to someone else, it would be understood to be completely within the rights of the supporting person to decide whether or not they would sacrifice their individual autonomy to help someone else. It is the same with abortion. Even if a foetus is a human being, because it relies on a pregnant woman to survive, it is at the discretion of the pregnant woman to decide whether supporting another life is possible or desirable at that time. The woman-shaming that the anti-abortion movement promotes is centered on devaluing the rights of women and discrediting a woman's ability to make choices that intimately affect her life (Arthur, 2003; Canadians for Choice, 
n.d.). The justification for such misogyny is based in patriarchy and is only countered by fearlessly supporting all aspects of women's rights.

Abortion rights activists advocate that a woman must have control over her reproductive health in order to be able to fully function as a self-determined person. Abortion rights activism is based in valuing women, valuing children and motherhood, and valuing the right to self-determination (Canadians for Choice, n.d). Typically, abortion activists advocate from a pro-choice perspective, a perspective that although based on the ideals of women's rights, is problematic.

The pro-choice perspective is problematic because of the language of "choice." Whereas rights are understood to be benefits that all people ought to have access to choices are connected to having resources and being able to exercise status (Solinger, 2001). When things, including abortion, are framed as choices, a hierarchy is created that determines who ought to be able to make choices (Smith, 2005; Solinger, 2001). In the case of abortion, poor women and women of colour continue to be discriminated against because proponents of the pro-choice movement often "do not take into consideration all the social, economic, and political conditions that frame the so-called choices that women are forced to make" (Smith, 2005, p. 127). For instance, when considering some of the barriers to abortion access, it is evident that women will be impacted differently. A woman living in an urban centre, with healthcare coverage and a supportive partner, will have a very different experience accessing abortion services than a woman who must spend time and money travelling from a rural location, a woman without healthcare coverage, or a woman without social support. The way a woman's racial, geographical and socioeconomic identities intersect can impede her ability to access abortion services. When this happens, "choice" becomes a statussymbol limited to White, middle class women. The pro-choice perspective is not relevant to those who do not fit into this narrow category. The solution to the limitations that exist within the current pro-choice perspective may lie in the paradigmatic understanding and advocacy of reproductive justice.

\section{An Intersectional Call to Action}

The theoretical framework of reproductive justice originated as an intersectional theory and call to action in response to the reproductive oppression of women (Ross, 2006). Motivated by the International Conference on Population and Development in Cairo in 1994, it was women of colour at the Illinois Pro-Choice Alliance in Chicago who first coined the term "reproductive justice," and since this time it has been members of the SisterSong Women of Color Reproductive Health Collective that have made it a popular and growing movement (Luna, 2010; Ross, 2006). The ideas behind reproductive justice are based on the historically valued womancentered reproductive practices and shared knowledge that was destroyed through colonization, industrialization and the imposition of patriarchy. 
Although the concepts embedded in the definition of reproductive justice are old, the popularization of the term signifies a renewed movement towards integrating reproductive health into social justice.

As a principle, reproductive justice recognizes the need for full-spectrum reproductive health care activism (Silliman, Fried, Ross \& Gutiérrez, 2004), yet in Canada, most of the work done in the name of "reproductive justice" seems to be abortion related. In order to truly combat reproductive oppression, the reproductive justice movement needs to universally advocate for abortion rights, equal access to reproductive health services, maternal rights and for understanding the relationship between reproductive health and women's empowerment. As a framework, reproductive justice provides the language, understanding and collectivity to bridge the current divide between abortion activism and birth activism. Traditionally, abortion rights activists may have recognized the need for the de-medicalization of birth, and birth activists may have recognized the need for abortion rights, but to date, I would argue that each activist group has been relatively self-serving. The reason for this is understandable; by being exclusive in their focus on only select reproductive health issues, activists become experts in their area of concern and well versed in articulating their key points. However, in a culture that is often blind to the multiple ways in which women continue to be oppressed, there needs to be a convergence of abortion and birth activists who understand and support each other's concerns and commit to working towards full-spectrum reproductive justice.

The affinity between abortion activism and birth activism is striking and centres on the fundamental belief that a woman ought to have complete control over her body and over her reproductive life. Unfortunately, women are rarely given the freedom to make reproductive choices that are free from pro-foetus, paternalistic rhetoric which places the value of a woman as secondary to the value of a foetus or to the beliefs of a physician (Wolf, 2003). A woman who has an abortion and a woman who chooses a less medicalized birth both face the possibility of social stigma and harassment. For example, a woman who has an abortion may face harassment by people who believe in the value of the foetus over the value of the woman, and a woman who chooses to have an unmedicated home birth may also face social stigma that extends from the mistaken belief that home births are less safe than hospital births. In reality, studies show that women who carry low-risk pregnancies fare well, if not better, when they are able to birth outside of a hospital (Ehrenreich \& English, 2005; Harper, 2005; Janssen et al., 2006; Klaus et al., 2002). In both cases, the concern of those who disagree with the woman's choices is based on a standpoint that favours the health and wellness of the foetus over the health and wellness of the woman.

Abortion activists and birth activists support a woman's right to make choices about her reproductive life in a context where she is informed, safe, and free from coercion (Klaus et al., 2002; Shaw, 2006). Furthermore, both abortion and birth activists work to promote the concepts of choice and informed consent and to help de-stigmatize the attitudes and judgements that 
surround reproductive health (Canadians for Choice, n.d.; Harper, 2005). For instance, abortion activists try to normalize abortion as a common experience that many women have. De-stigmatizing abortion means opposing the belief that abortion is shameful, in spite of its being a personal aspect of life that is normal and often necessary. Normalizing abortion does not mean that it ought to be considered insignificant due to its prevalence, and respect for a variety of emotions surrounding abortion experiences is key to supporting women (Canadians for Choice, n.d.). I would argue that normalizing abortion simply means that, as a procedure that many women go through, it needs to be recognized and respected as a potential part of any woman's life. Similarly, normalizing childbirth and breastfeeding is important to birth activists. The ability that women have to give birth is highlighted by birth activists, and the benefits of having an unmedicated birth are thoroughly discussed (Harper, 2005; Klaus et al., 2002). The natural benefits of breastfeeding are also promoted, and by emphasizing the normality of feeding a baby in public, activists and mothers work to deconstruct the social taboo of public breastfeeding, and promote the wellness of mothers and babies. Challenging the stigmatizing and oppressive attitudes that surround abortion and demedicalized birth in society is not an easy task, but it is a necessary one.

Like many reproductive justice activists, I too would argue that there are inherent problems with each activist group. The current pro-choice movement often fails to recognize how it is exclusive, marginalizing, and does not address the realities of many women. The current birth movement often fails to emphasize the importance of women having control over all aspects of their pregnancy, beginning with whether or not to continue it. Working through these dichotomized frameworks does not address the needs of women (Ross, 2006; Silliman, Fried, Ross \& Gutiérrez, 2004). In fact, if empowering women is the goal, abortion rights and birth rights must be recognized as inseparable.

Abortion rights activists and birth activists seek to end reproductive oppression. By combining women's knowledge about pregnancy and birth with woman-centered medical care that is used appropriately and through informed consent, women can regain control over their reproductive health and lives (Harper, 2005). Reproductive rights are human rights, and it is unethical to support only some of the rights that are so important for all women. In order for women to experience true emancipation from reproductive oppression, supporters of the abortion rights movement and supporters of birth activism must work together to sustain a movement that advocates for full-spectrum reproductive justice (Silliman, Fried, Ross \& Gutiérrez, 2004). To continue to work as though abortion and birth are separate issues divides the women's rights movement and allows for the continuation of reproductive oppression. Full-spectrum reproductive justice is the only movement that fully recognizes women's intersecting identities and respects the full range of women's reproductive health needs. Women can regain control over their reproductive lives, but need the support of a unified movement. In a culture where colonization, industrialization and 
patriarchy have appropriated women's knowledge and women's rights, it is time for a reproductive revolution.

\section{References}

Agnew, T., Gilmore, J., \& Sullivan, P. (1997). A multicultural perspective on breastfeeding of Canada. Ottawa, ON: Health Canada.

Arthur, J. (2003) Where is the anti-choice movement headed? Pro-Choice Press. Retrieved from http://www.prochoiceactionnetwork-canada.org/prochoicepress/03summer.shtml

Baker, S., Choi, P., Henshaw, C., \& Tree, J. (2005). 'I felt as though I'd been in jail': Women's experiences of maternity care during labour, delivery and the immediate postpartum. Feminism \& Psychology, 15(3), 315-342. doi: 10.1177/0959-353505054718

Barber, K. (Ed.). (2004) Supine. Canadian Oxford dictionary ( $2^{\text {nd }}$ ed.). Don Mills, ON: Oxford University Press.

Bergeron, V. (2007). The ethics of caesarean section on maternal request: a feminist critique of the American College of Obstetricians and Gynecologists' position paper on patient-choice surgery. Bioethics, 21, (9), 478-487.

Brodsky, P. (2008) Women versus medicine through the ages: The control of childbirth. Jefferson, NC: McFarland \& Company, Inc.

Bryan, A.D., Aiken, L.S., \& West, S.D. (1997). Young women's condom use: The influence of acceptance of sexuality, control over the sexual encounter, and perceived susceptibility to common STDs. Health Psychology, 16(5), 468-479.

Canadian Association of Midwives. (2012). Midwifery in Canada - Provinces/territories. Retrieved from http://www.canadianmidwives.org/province/Alberta.html

Canadians for Choice. (n.d.). Common myths about abortion. Ottawa, ON: Canadians for Choice.

Canadian Institute for Health Information. (2012). Induced abortion performed in Canada in 2010. Retrieved from http://www.cihi.ca/CIHI-ext-portal/pdf/internet/TA_10_ ALLDATATABLES20120417_EN

Carlton, T., Callister, L.C., Stoneman, E. (2005). Decison making in laboring women: Ethical issues for perinatal nurses. Journal of Perinatal Neonatal Nursing, 19(2), 145-154

CBC News. (2008a). Breastfeeding mother alleges WestJet harassment. CBC News. Retrieved from http://www.cbc.ca/canada/british-columbia/story/2008/08/06/bc-breast-feeding-coverup-west-jet-.html

CBC News. (2008b). H\&M breastfeeding incident sparks human rights protest. CBC News. Retrieved from http://www.cbc.ca/health/story/2008/08/05/bc-breastfeeding-protest-h-mvancouver.html

CBC News. (2010). Abortions require anonymity, says P.E.I. group. CBC News. Retrieved from http://www.cbc.ca/canada/prince-edward-island/story/2010/12/06/pei-abortion-anonymity-584. html

Chaillet, N., Dubé, E., Dugas, M., Francoeur, D., Dubé, J., Gagnon, S., . . Dumont, A. (2007). Identifying barriers and facilitators towards implementing guidelines to reduce caesarean section rates in Quebec. Bulletin of the World Health Organization, 85(10), 733-820.

Choi, K., Wojcicki, J., \& Valencia-Garcia, D. (2004). Introducing and negotiating the use of female condoms in sexual relationships: Qualitative interviews with women attending a family planning clinic. AIDS and Behavior, 8(3), 251-261

Chowdhury, M., Koblinsky, M., Moran, A., \& Ronsmans, C. (2012). Maternal morbidity and disability and their consequences: neglected agenda in maternal health. Journal of Health Population and Nutrition, 30(2), 124-130.

Cohain, J.S. (2007). Management of care: Different outcomes. Midwifery Today, 82,19-21.

Connors, A. (2010). Significant fall in global maternal mortality. Irish Medical Times, 44(42), 57.

Craven, C. (2010). Pushing for midwives: Homebirth mothers and the reproductive rights movement. Philidelphia, PA: Temple University Press.

Ehrenreich, B. \& English, D. (2005). For her own good: Two centuries of experts' advice to women ( $2^{\text {nd }}$ ed.). New York: Anchor Books, Random House Inc.

Flaherty, D. (2003). Canadian institute for health information: Privacy impact assessment of the therapeutic abortions database. Ottawa, ON: Canadian Institute for Health Information. 
Goldberg, H. (2009). Informed decision making in maternity care. Journal of Perinatal Education, 18(1), 32-40.

Guttmacher Institute. (2010). Facts on induced abortion in the United States. Retrieved from http://www.guttmacher.org/pubs/fb_induced_abortion.html

Hardin, A.M., \& Buckner, E.B. (2004). Characteristics of a positive experience for women who have unmedicated childbirth. The Journal of Perinatal Education, 13 (4), 10-16.

Harper, B. (2005). Gentle birth choices ( $2^{\text {nd }}$ ed.). Rochester: Healing Arts Press.

International Planned Parenthood Federation. (2006) Death and denial: Unsafe abortion and poverty. London, UK: International Planned Parenthood Federation.

Janssen, P.A., Carty, E.A., \& Reime, B. (2006). Satisfaction with planned place of birth among midwifery clients in British Columbia. Journal of Midwifery and Women's Health, 51, (2), 91-97.

Janssen, P.A., Henderson, A.D., \& Vedam, S. (2009). The experience of planned home birth: Views of the first 500 women. Birth, 36(4), 297-304.

Jordan, R.G., \& Murphy, P.A. (2009). Risk assessment and risk distortion: Finding the balance. Journal of Midwifery \& Women's Health, 54(3), 191-200.

Kalichman, S.C., Williams, E.A., Cherry, C., Belcher, L., \& Nachimson, D. (1998). Sexual coercion, domestic violence, and negotiating condom use among low-income African American women. Journal of Women's Health, 7(3), 371-378.

Klaus, M.H., Kennell, J.H., \& Klaus, P.H. (2002). The doula book ( $2^{\text {nd }}$ ed.). Cambridge: Da Capo Press.

Koyama, A., \& Williams, R. (2005). Abortion in medical school curricula. McGill Journal of Medicine, 8(2), 157-160.

Lahood, G. (2007). From 'bad' ritual to 'good' ritual: Transmutations of childbearing trauma in holotropic ritual. Journal of Prenatal and Perinatal Psychology and Health, 22(2), 81-112.

Lothian, J. (2006). Birth plans, the good, the bad, and the future. Journal of Obstetric, Gynecologic, \& Neonatal Nursing, 35(2), 295-303.

Lowe, N.K. (2004). Context and process of informed consent for pharmacologic strategies in labor pain care. Journal of Midwifery and Women's Health, 49(3), 250-259.

Luna, Z. (2010). Marching toward reproductive justice: Coalitional (re) framing of the March for Women's Lives. Sociological Inquiry, 80(4), 554-578. doi: 10.1111/j.1475682X.2010.00349.x

Minister of Public Works and Government Services Canada. (2002). A practical workbook to protect, promote and support breastfeeding in community based projects. Ottawa, ON: Health Canada.

Muir, S., Larner, J.N., Bee, D.B., Joseph, G., Calvert, L.K., Slamen, J., \& Muir, S.K. (2010) Hey Facebook, breastfeeding is not obscene (Official petition to Facebook). Facebook. Retrieved from http://www.facebook.com/?ref=home\#!/group.php?gid=2517126532\&v=info

Munro, S., Kornelsen, J., \& Hutton, E. (2009). Decision making in patient-initiated elective caesarean delivery: the influence of birth stories. Journal of Midwifery and Women's Health, 54, 373-379.

Parry, D.C. (2008). "We wanted a birth experience, not a medical experience": Exploring Canadian Women's Use of Midwifery. Health Care for Women International, 29(8), 784-806.

Price, S., Noseworthy, J., \& Thornton, J. (2007). Women's experience with social presence during childbirth. The American Journal of Maternal/Child Nursing, 32(3), 184-191.

Ross, L. (2006). Understanding reproductive justice. Atlanta, GA: SisterSong Women of Color Reproductive Health Collective.

Roth, L.M., \& Henley, M.M. (2012). Unequal motherhood: Racial-ethnic and socioeconomic disparities in cesarean sections in the United States. Social Problems, 59(2), 207-227. doi: 10.1525/sp.2012.59.2.207

Shaw, J. (2006). Reality check: a close look at accessing abortion services in Canadian hospitals. Ottawa, ON: Canadians for Choice.

Shaw, J., Ormiston, A., \& Weeds, C. (2008). 10 Years in Ontario Women's Reproductive Health: Abortion Access, Midwifery and Birth Control. Toronto: Ontario Women's Health Network.

Silliman, J., Fried, M.G., Ross, L., \& Gutiérrez, E.R. (2004) Undivided rights: Women of color organize for reproductive justice. Cambridge, MA: South End Press.

Smith, A. (2005). Beyond pro-choice versus pro-life: Women of color and reproductive justice. National Women's Studies Association Journal, 17(1), 119-140.

Society of Obstetricians and Gynaecologists of Canada, Association of Women's Health, 
Obstetric and Neonatal Nurses of Canada, Canadian Association of Midwives, College of Family Physicians of Canada, and Society of Rural Physicians of Canada. (2008). Joint policy statement on normal childbirth. Journal of Obstetrics and Gynaecology of Canada, 30(12), 1163-1165.

Solinger, R. (2001) Beggars and choosers: How the politics of choice shapes adoption, abortion, and welfare in the United States. New York, NY: Hill and Wang.

Spoel, P., \& James, S. (2006) Negotiating public and professional interests: a rhetorical analysis of the debate concerning the regulation of midwifery in Ontario, Canada. Journal of Medical Humanities, 27, 167-186. doi: 10.1007/s10912-006-9016-7

Staggenborg, S. (1991). The pro-choice movement: Organization and activism in the abortion conflict. New York, NY: Oxford University Press, Inc.

Statistics Canada. (2008, May 21). Induced abortions. The Daily. Retrieved from http://www. statcan.gc.ca

The Childbirth by Choice Trust (Eds.). (1998). No choice: Canadian women tell their stories of illegal abortion. Toronto, ON: The Childbirth by Choice Trust.

Wolf, N. (2003) Misconceptions: Truth, lies, and the unexpected on the journey to motherhood. New York, NY: Anchor Books.

Wu, F., \& Arthur, J. (2010). A survey of anti-choice protesting activity at Canadian abortion clinics. Vancouver, BC: Abortion Rights Coalition of Canada. 